\section{Commentary: To cut is a chance to cure? Lessons to be learned from the PulMiCC trial}

\author{
Katherine D. Gray, MD, and Daniela Molena, MD
}

For most cancer types, surgical resection is the sole curative therapy. Increasingly, nonprimary tumor resections, including local recurrences, oligometastatic disease, and even operative debulking of widespread tumor implants, are being performed. ${ }^{1}$ Colorectal cancer has shown a benefit to resection of liver and lung metastases, with 5-year survival of approximately $41 \% .^{2}$ Given this context, Tom Treasure's 2019 randomized controlled PulMiCC trial, a call to reconsider pulmonary metastasectomy in colorectal cancer, is a provocative break from accepted surgical practice. ${ }^{3}$ In this follow-up commentary, Treasure and colleagues discuss the rationale for the trial and the importance of reexamining surgical dogma. ${ }^{4}$

The strength and the failure of the PulMiCC trial is randomization. The authors determined equipoise of a nonsurgical option from a few small trials and predictions of a mathematical model suggesting that watchful waiting may have acceptable outcomes. However, unsurprisingly, the recruitment goal was not met, largely owing to the clinicians' decision to not randomize. Despite the planned participation of 24 medical centers and enrollment of more than 500 patients, only 65 patients from 13 hospitals were ultimately analyzed, almost $30 \%$ from one center. Results comparing metastasectomy to active surveillance showed overlapping survival curves, with a 5 -year survival of $38 \%$ in the intervention group and $29 \%$ in the control

\footnotetext{
From the Thoracic Service, Department of Surgery, Memorial Sloan Kettering Cancer Center, New York, NY.

Disclosures: Dr Molena reports receiving consulting fees from Intuitive, Urogen, Boston Scientific, and Johnson and Johnson and serving on a steering committee for AstraZeneca. Dr Gray reported no conflicts of interest. This work was supported in part by National Cancer Institute Grant P30 CA008748.

The Journal policy requires editors and reviewers to disclose conflicts of interest and to decline handling or reviewing manuscripts for which they may have a conflict of interest. The editors and reviewers of this article have no conflicts of interest.

Received for publication Feb 3, 2021; revisions received Feb 3, 2021; accepted for publication Feb 4, 2021; available ahead of print Feb 16, 2021

Address for reprints: Daniela Molena, MD, Thoracic Service, Department of Surgery,

Memorial Sloan Kettering Cancer Center, 1275 York Ave, New York, NY 10065

(E-mail: molenad@mskcc.org).

J Thorac Cardiovasc Surg 2022;163:493-4

$0022-5223 / \$ 36.00$

Copyright (c) 2021 by The American Association for Thoracic Surgery

https://doi.org/10.1016/j.jtcvs.2021.02.015
}

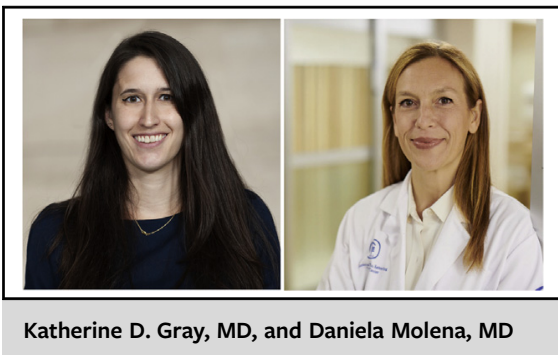

\section{CENTRAL MESSAGE \\ The PulMiCC trial is unable to overturn surgical dogma for pulmonary resection of colo- rectal metastases.}

group. The sample size was inadequate to show equivalence of the surveillance arm, and even so, the difference between the 2 groups fell almost outside the predetermined $10 \%$ noninferiority threshold at 5 years.

The authors argue that despite these limitations, the data are still sufficient to show that survival for patients with oligometastatic disease is higher than previously believed, despite the sparse use of systemic therapy in either group. This finding is likely due to the fact that resectable metastatic disease represents a unique and indolent tumor biology that is distinct from the disease in the majority of patients with distant metastases. Parallels can be drawn to indolent tumors such as thyroid cancer, in which lung metastases are often surveilled for years without clinical impact, or prostate cancer, which is often slow-growing and managed with observation. However, less than one-third of patients in the observation arm are alive at 5 years, suggesting that unlike patients with thyroid or prostate cancer, these patients are eventually dying of disease. In contrast, a retrospective review of pulmonary metastasectomy for colorectal cancer with optimal adjuvant systemic therapy showed 5-year survival as high as $66 \%$ and long-term survival up to 20 years after resection - in other words, surgery for metastases can be done with curative intent. ${ }^{5}$

Because of the difficulty in enrollment, which would undoubtedly plague attempts to repeat this study, it is likely that the PulMiCC trial will be the definitive randomized trial of oligometastatic disease with a true control group. What conclusions can be drawn? The behavior of resectable metastatic disease is unique, and 5-year survival is possible in some patients without surgical therapy, making it a consideration especially for poor surgical candidates. Will this 
study change practice? Unlikely. After all, for pulmonary metastases in colorectal cancer, to cut is a chance to cure.

\section{References}

1. Stewart CL, Warner S, Ito K, Raoof M, Wu GX, Kessler J, et al. Cytoreduction for colorectal metastases: liver, lung, peritoneum, lymph nodes, bone, brain. When does it palliate, prolong survival, and potentially cure? Curr Probl Surg. 2018; 55:330-79.

2. Gonzalez M, Poncet A, Combescure C, Robert J, Ris HB, Gervaz P. Risk factors for survival after lung metastasectomy in colorectal cancer patients: a systematic review and meta-analysis. Ann Surg Oncol. 2013;20:572-9.
3. Treasure T, Farewell V, Macbeth F, Monson K, Williams NR, Brew-Graves C, et al. Pulmonary metastasectomy versus continued active monitoring in colorectal cancer (PulMiCC): a multicentre randomised clinical trial. Trials. 2019; 20:718.

4. Treasure T, Dunning J, Williams NR, Macbeth F. Lung metastasectomy for colorectal cancer: the impression of benefit from uncontrolled studies was not supported in a randomized controlled trial. J Thorac Cardiovasc Surg. 2022;163: 486-90.

5. Nakajima J, Iida T, Okumura S, Horio H, Asamura H, Ozeki Y, et al. Recent improvement of survival prognosis after pulmonary metastasectomy and advanced chemotherapy for patients with colorectal cancer. Eur J Cardiothorac Surg. 2017; 51:869-73. 